\title{
Appraisal of long-time outcomes after curative surgery in elderly patients with gastric cancer: a propensity score matching analysis
}

Tomoyuki Matsunaga ${ }^{1 *}$, Ryo Ishiguro', Wataru Miyauchi ${ }^{1}$, Yuji Shishido ${ }^{1}$, Kozo Miyatani $^{1}$, Manabu Yamamoto ${ }^{1}$, Naruo Tokuyasu', Shuichi Takano' ${ }^{1}$, Teruhisa Sakamoto ${ }^{1}$, Soichiro Honjo ${ }^{1}$, Hiroaki Saito ${ }^{2}$ and Yoshiyuki Fujiwara ${ }^{1}$

\begin{abstract}
Background: This study was conducted to assess the long-term outcomes of elderly patients among propensityscore-matched gastric cancer patients after curative gastrectomy and to propose the proper management of elderly gastric cancer patients.

Methods: We enrolled 626 patients with gastric cancer who underwent curative gastrectomy at our institution between January 2004 and December 2015. To minimize selection bias among 2 groups, propensity score matching was performed.

Results: Patients were divided into an elderly group over 75 years old (EP group; $\mathrm{n}=186$ ) and a non-elderly group (NEP group; $n=440)$. After propensity score matching, patients were divided into EP group $(n=178)$ and NEP group $(n=175)$. Five-year overall survival was significantly lower in the EP group than in the NEP group, consistent with a subgroup analysis of each stage. However, the 5-year disease-specific survival among all enrolled patients and those with stage I and II disease did not differ significantly. Moreover, in the subgroup of stage III patients, 5 year diseasespecific survival was significantly lower in the EP group (23.0\%) than in the NEP group (59.4\%; $P=0.004)$. Because elderly patients with stage III disease had an extremely poor prognosis, we decided to compare the two groups with stage III. The EP group contained significantly fewer patients with D2 lymphadectomy $(P=0.002)$ and adjuvant chemotherapy $(P<0.001)$ than the NEP group. $C$-reactive protein to albumin ratio was significantly higher in patients in the EP group than in the NEP group $(P=0.046)$, and the prognostic nutritional index was significantly lower in patients in the EP group than in the NEP group $(P=0.045)$. Multivariate analysis revealed that the prognostic nutritional index and lymphatic invasion were independent prognostic factors.

Conclusions: Elderly gastric cancer patients with stage III disease showed poorer disease-specific survival compared with non-elderly patients, which may be due to a poorer nutritional and inflammatory background, fewer D2 lymphadenectomies, and a lack of adjuvant chemotherapy. The safe induction of standard lymphadenectomy and adjuvant chemotherapy with perioperative aggressive nutritional support may improve the prognosis of elderly gastric cancer patients with stage III disease.
\end{abstract}

\footnotetext{
*Correspondence: matut0m0@tottori-u.ac.jp

${ }^{1}$ Division of Gastrointestinal and Pediatric Surgery, Department

of Surgery, School of Medicine, Tottori University Faculty of Medicine,

Yonago 683-8504, Japan

Full list of author information is available at the end of the article
}

(C) The Author(s) 2021. Open Access This article is licensed under a Creative Commons Attribution 4.0 International License, which permits use, sharing, adaptation, distribution and reproduction in any medium or format, as long as you give appropriate credit to the original author(s) and the source, provide a link to the Creative Commons licence, and indicate if changes were made. The images or other third party material in this article are included in the article's Creative Commons licence, unless indicated otherwise in a credit line to the material. If material is not included in the article's Creative Commons licence and your intended use is not permitted by statutory regulation or exceeds the permitted use, you will need to obtain permission directly from the copyright holder. To view a copy of this licence, visit http://creativecommons.org/licenses/by/4.0/. The Creative Commons Public Domain Dedication waiver (http://creativeco mmons.org/publicdomain/zero/1.0/) applies to the data made available in this article, unless otherwise stated in a credit line to the data. 
Keywords: Elderly patient, Gastric cancer, Prognosis

\section{Background}

Gastric cancer is the fourth most common cancer in the world and the second leading cause of cancer-related deaths, while the number of elderly gastric cancer patients is reported to be increasing [1,2]. Advances in surgery, anesthesia, and pre- and post-operative management have led to an increase in gastrectomies conducted on elderly patients. Surgeons sometimes have difficulties in deciding upon the surgery of elderly patients because elderly patients are poorly nourished and have a variety of comorbidities [3]. For these reasons, although curative surgery with standard lymph node dissection is important in gastrectomy, surgeons often refrain from lymph node dissection because elderly patients might experience serious postoperative complications $[4,5]$. However, there are few studies evaluated outcomes after operation of gastric cancer in elderly patients, and whether lymph node dissection is associated with poor cancer prognosis is unclear.

Adjuvant chemotherapy is necessary to improve survival in advanced gastric cancer patients after curative surgery [6]. The efficacy of adjuvant chemotherapy in gastric cancer has been demonstrated by various randomized control trials [6-8]. Chemotherapy is toxic and can cause serious side effects, while age is associated with increased toxicity and is considered a risk factor for reduced tolerance to chemotherapy. Despite the increase in elderly gastric cancer patient populations, there are few reports that indicate the efficacy of chemotherapy for elderly patients. Various clinical trials often enroll fewer elderly patients or exclude them altogether. The efficacy of limited lymph node dissection and adjuvant chemotherapy is unclear in patients with stage III disease where recurrence risk is high.

This study was conducted to assess the long-term outcomes of elderly patients among propensity-scorematched gastric cancer patients after curative gastrectomy and to propose the proper management of elderly gastric cancer patients.

\section{Methods}

\section{Patients}

This retrospective study was performed at Tottori University Hospital from January 2004 to December 2015, during which 626 gastric cancer patients underwent curative gastrectomy. The Japanese Gastric Cancer Treatment Guidelines were used to determine tumor status and the degree of lymph node dissection [9].
Patients with other primary cancers, distant metastases, and neoadjuvant chemotherapy were excluded from this study. Patients over 75 years old were defined as the elderly patient (EP) group, and patients under 75 years old were defined as the non-elderly patient (NEP) group. The modified frailty index (mFI) and Charlson comorbidity index (CCI) was calculated [10, 11]. To minimize selection bias among 2 groups, propensity score matching was performed with a logistic regression model and a 1:1 nearest neighbor-matching using MatchIt package on $\mathrm{R}$ version 3.6.3 software. The following variables were selected and matched as matching variables because these variables were determined to have a significant survival impact: sex (male, female), depth of tumor invasion (T1, T2, T3, T4), lymph node metastasis (N0, N1, N2, N3), lymphatic invasion (positive, negative), venous invasion (positive, negative), histologic type (differentiated, undifferentiated), type of gastrectomy (partial gastrectomy, total gastrectomy, proximal gastrectomy), and pathological stage (I, II, III). In addition, patients who had removed less than 16 lymph nodes were excluded from the analysis.

\section{Surgical procedures and postoperative management}

Gastrectomy was performed with D2 lymph node dissection for advanced cancer and D1 + lymph node dissection for early gastric cancer according to the Japanese gastric cancer treatment guidelines [9]. However, the refrain of lymph node dissection for surgery in the elderly or highrisk patients was determined by physician. The indication for adjuvant chemotherapy is patients with pathological stage II and stage III disease excluding T3N0 [9]. The adjuvant chemotherapy was based on oral 5-fluorouracil derivatives without the combination of other agents. Indications for adjuvant chemotherapy, including elderly patients, were those with preserved organ function, Eastern Cooperative Oncology Group Performance Status 0 or 1 , and adequate oral intake, and consent was obtained from each patient. Patients were periodically checked for recurrence via physical examination and blood tests every 3 months after discharge from the hospital. Computed tomography $(\mathrm{CT})$ was performed at least every 6 months after surgery. The recurrence patterns and causes of death were examined from clinical records, CT, and positron emission tomography $\mathrm{CT}$. In patients who were difficult to follow, we made direct enquires with their families. 


\section{Definition of inflammation-based factors}

The findings of peripheral blood tests, such as serum albumin level, total white blood cell count, total platelet count (PC), lymphocyte count (LC), and neutrophil count (NC) were collected from patients' records. Preoperative blood tests were performed within 5 days before surgery. The platelet-to-lymphocyte ratio (PLR) and neutrophil-to-lymphocyte ratio (NLR) and were obtained by dividing the peripheral $\mathrm{PC}$ and $\mathrm{NC}$ by the peripheral LC, respectively [12]. The prognostic nutritional index (PNI) was calculated as follows: $10 \times$ ALB concentration $+0.005 \times$ total LC [13]. The CRP/ALB ratio (CAR) was calculated by dividing the CRP level by the ALB level (CRP measured in $\mathrm{mg} / \mathrm{L}$ and albumin measured in $\mathrm{g} / \mathrm{L}$ ) [14]. The Youden index was calculated using receiver operating characteristic (ROC) analysis, to determine optimal cutoffs for CAR, NLR, and PNI in the 5-year disease-specific survival analysis.

\section{The definition of complications}

The Clavien-Dindo (CD) system was used to determine postoperative complications [15]. In this study, postoperative complications were defined as those of CD classification grade II or more occurring within 30 days after surgery. If multiple complications occurred, a higher $\mathrm{CD}$ classification was used in the present study.

\section{Statistical analysis}

Categorical variables were compared via $\chi^{2}$ test or Fisher's exact tests. Mann-Whitney U test was used to compare continuous data, which was expressed as mean \pm standard deviation. The time from the date of surgery until death from any cause, including death resulting from another disease, was defined as overall survival (OS). Survival curves were calculated using the Kaplan-Meier method, and differences between survival curves were examined using the log-rank test. Cox's proportional hazards model was used for univariate and multivariate analyses of factors considered prognostic for disease-specific survival (DSS). $P<0.05$ was considered significant. All reported statistical analyses were performed using JMP v9.0.1 software (SAS Institute, Inc., Cary, NC, USA).

\section{Results}

\section{Patient characteristics}

Overall, there were 450 (71.9\%) male and 176 (28.1\%) female patients, and their median age was $67.8 \pm 11.5$ years (range, 27-93). The pathological disease stages were I, II, and III in 432, 115, and 79 patients, respectively. Patients were divided into an elderly group over 75 years old (EP group; $n=186$ ) and a non-elderly group (NEP group; $n=440$ ). The relationships between the age and clinicopathological variables of the patients are shown in Table 1. As for histology, the EP group included more patients with differentiated-type carcinoma compared with the NEP group $(P=0.005)$. The EP group included significantly less patients with CCI low compared with the NEP group $(P<0.001)$, and $\mathrm{mFI}$ were significantly higher in patients in the EP group than in those in the NEP group $(P<0.001)$. Positive venous invasion was significantly higher in patients in the EP group than in those in the NEP group $(P=0.004)$. The EP group contained significantly fewer patients who underwent D2 lymphadectomy $(P=0.005)$ and adjuvant chemotherapy $(P<0.001)$ than the NEP group. Death from another disease was significantly higher in patients in the EP group than in those in the NEP group $(P<0.001)$. CAR and NLR were significantly higher in the EP group than in those in the NEP group $(P<0.001, P=0.002$, respectively). PNI was significantly lower in the EP group than in those in the NEP group $(P<0.001)$. No significant differences were observed regarding sex, tumor size, type of gastrectomy, approach, depth of tumor invasion, lymph node metastasis, lymphatic invasion, pathological stage, death from primary disease, and PLR. After propensity score matching, 19 patients (8 patients; EP group, 11 patients; NEP group) were excluded because lymph node had been dissected less than 16, and all excluded patients were stage I. Finally, 353 patients were selected for analysis. No significant differences were observed between the two groups except for age, CCI, mFI, lymphadectomy, adjuvant chemotherapy, death from another disease, CAR, NLR, and PNI (Table 1).

\section{Postoperative long-term outcomes}

The 5-year OS rate was significantly lower in the EP group (68.5\%) than in the NEP group (84.1\%; $P<0.001$; Fig. 1a) in all patients enrolled in this study. The significantly worse OS in the EP group was also observed in subgroups with stage I (Fig. 1b), stage II (Fig. 1c), and stage III (Fig. 1d) disease. However, the 5-year DSS among all enrolled patients and those with stage I and II disease did not differ significantly (all stage, $P=0.067$, Fig. 2a; stage I, $P=0.821$, Fig. 2b; stage II, $P=0.684$, Fig. 2c). Moreover, in the subgroup of stage III patients, 5-year DSS was significantly lower in the EP group (23.0\%) than in the NEP group (59.4\%; $P=0.004$, Fig. $2 \mathrm{~d})$.

\section{Patient characteristics in stage III disease}

Because elderly patients with stage III disease had an extremely poor prognosis, we decided to compare the two groups with stage III. The clinicopathological characteristics of stage III patients are summarized in Table 2. No marked differences were observed in sex, CCI, mFI, tumor size, depth of tumor invasion, 
Table 1 Clinicopathological features of patients in the EP group and NEP group before and after propensity score matching

\begin{tabular}{|c|c|c|c|c|c|c|}
\hline \multirow[t]{2}{*}{ Characteristics } & \multicolumn{3}{|l|}{ Before matching } & \multicolumn{3}{|l|}{ After matching } \\
\hline & EP group $(n=186)$ & NEP group $(n=440)$ & $p$ value & EP group $(n=178)$ & NEP group $(n=175)$ & $p$ value \\
\hline Age (years) & $80.0 \pm 4.1$ & $62.6 \pm 9.5$ & $<0.001$ & $80.2 \pm 4.0$ & $63.8 \pm 9.0$ & $<0.001$ \\
\hline Sex & & & 0.206 & & & 0.473 \\
\hline Male & $127(68.3)$ & $323(73.4)$ & & $123(69.1)$ & $127(72.6)$ & \\
\hline Female & $59(31.7)$ & $117(26.6)$ & & $55(30.9)$ & $48(27.4)$ & \\
\hline $\mathrm{CCl}$ & & & $<0.001$ & & & 0.002 \\
\hline Low & $65(34.9)$ & $243(55.2)$ & & $64(36.0)$ & $91(52.0)$ & \\
\hline Moderate/severe & $121(65.1)$ & $197(44.8)$ & & $114(64.0)$ & $84(48.0)$ & \\
\hline $\mathrm{mFl}$ & $0.074 \pm 0.068$ & $0.046 \pm 0.061$ & $<0.001$ & $0.073 \pm 0.067$ & $0.050 \pm 0.064$ & $<0.001$ \\
\hline Number of analyzed lymph nodes & & & 0.577 & & & \\
\hline$<16$ & $8(4.3)$ & $21(4.7)$ & & 0 & 0 & \\
\hline$\geq 16$ & $178(95.7)$ & $419(95.3)$ & & 178 & 175 & \\
\hline Number of positive lymph nodes & $1.75 \pm 5.34$ & $1.62 \pm 5.90$ & 0.546 & $1.70 \pm 4.80$ & $2.13 \pm 8.04$ & 0.738 \\
\hline Tumor size (mm) & $40.4 \pm 25.9$ & $38.9 \pm 25.6$ & 0.470 & $40.5 \pm 25.5$ & $41.3 \pm 26.3$ & \\
\hline Depth of tumor invasion & & & 0.479 & & & 0.956 \\
\hline $\mathrm{T} 1$ & $115(61.8)$ & $288(65.5)$ & & $107(60.1)$ & $108(61.7)$ & \\
\hline $\mathrm{T} 2$ & $26(14.0)$ & $49(11.1)$ & & $26(14.6)$ & $22(12.6)$ & \\
\hline $\mathrm{T} 3$ & $33(17.7)$ & $84(19.1)$ & & $33(18.5)$ & $34(19.4)$ & \\
\hline $\mathrm{T} 4$ & $12(6.5)$ & $19(4.3)$ & & $12(6.8)$ & $11(6.3)$ & \\
\hline Lymph node metastasis & & & 0.765 & & & 0.700 \\
\hline Positive & $51(27.4)$ & $112(25.5)$ & & $49(27.5)$ & $46(26.3)$ & \\
\hline Negative & $135(72.6)$ & $328(74.5)$ & & $129(72.5)$ & $129(73.7)$ & \\
\hline Histologic type & & & 0.005 & & & 0.511 \\
\hline Differentiated & $116(62.4)$ & $220(50.0)$ & & $111(62.4)$ & $115(65.7)$ & \\
\hline Undifferenciated & $70(37.6)$ & $220(50.0)$ & & $67(37.6)$ & $60(34.3)$ & \\
\hline Lymphatic invasion & & & 0.136 & & & 0.845 \\
\hline Positive & $110(59.1)$ & $231(52.5)$ & & $106(59.6)$ & $106(60.6)$ & \\
\hline Negative & $76(40.9)$ & $209(47.5)$ & & $72(40.4)$ & $69(39.4)$ & \\
\hline Venous invasion & & & 0.004 & & & 0.973 \\
\hline Positive & $102(54.8)$ & $184(41.8)$ & & $100(56.2)$ & $98(56.0)$ & \\
\hline Negative & $84(45.2)$ & $256(58.2)$ & & $78(43.8)$ & $77(44.0)$ & \\
\hline Stage of disease & & & 0.550 & & & 0.578 \\
\hline I & $124(66.7)$ & $308(70.0)$ & & $116(65.2)$ & $119(68.0)$ & \\
\hline$\|$ & $39(21.0)$ & $76(17.2)$ & & $39(21.9)$ & $31(17.7)$ & \\
\hline III & $23(11.3)$ & $56(12.8)$ & & $23(12.9)$ & $25(14.3)$ & \\
\hline Type of gastrectomy & & & 0.508 & & & 0.951 \\
\hline Distal & $131(70.4)$ & $325(73.9)$ & & $125(70.2)$ & $125(71.4)$ & \\
\hline Total & $34(18.3)$ & $64(14.5)$ & & $34(19.1)$ & $33(18.9)$ & \\
\hline Proximal & $21(11.3)$ & $51(11.6)$ & & 19 10.7) & $17(9.7)$ & \\
\hline Approach & & & 0.476 & & & 0.101 \\
\hline Open & $71(38.2)$ & $183(41.6)$ & & $67(37.6)$ & $82(46.9)$ & \\
\hline Laparo & $115(61.8)$ & $257(58.4)$ & & $111(62.4)$ & $93(53.1)$ & \\
\hline Lymphadectomy & & & 0.005 & & & 0.006 \\
\hline$<\mathrm{D} 2$ & $136(73.1)$ & $293(66.6)$ & & $130(73.0)$ & $103(58.9)$ & \\
\hline D2 & $50(26.9)$ & $147(33.4)$ & & $48(27.0)$ & $72(41.1)$ & \\
\hline Adjuvant chemotherapy & & & $<0.001$ & & & $<0.001$ \\
\hline Present & $12(6.5)$ & $84(19.1)$ & & $11(6.2)$ & $37(21.1)$ & \\
\hline Absent & $174(93.5)$ & $356(80.9)$ & & $167(93.8)$ & $138(78.9)$ & \\
\hline
\end{tabular}


Table 1 (continued)

\begin{tabular}{|c|c|c|c|c|c|c|}
\hline \multirow[t]{2}{*}{ Characteristics } & \multicolumn{3}{|l|}{ Before matching } & \multicolumn{3}{|l|}{ After matching } \\
\hline & EP group $(n=186)$ & NEP group $(n=440)$ & $p$ value & EP group $(n=178)$ & NEP group $(n=175)$ & $p$ value \\
\hline Death from another disease & & & $<0.001$ & & & 0.022 \\
\hline Present & $33(17.7)$ & $37(8.4)$ & & $31(17.4)$ & $16(9.1)$ & \\
\hline Absent & $153(82.3)$ & $403(91.6)$ & & $147(82.6)$ & $159(90.9)$ & \\
\hline Death from primary disease & & & 0.189 & & & 0.342 \\
\hline Present & $23(12.4)$ & $39(8.9)$ & & $23(12.9)$ & $17(9.7)$ & \\
\hline Absent & $163(87.6)$ & $401(91.1)$ & & $155(87.1)$ & $158(90.3)$ & \\
\hline CAR & $0.127 \pm 0.342$ & $0.066 \pm 0.176$ & $<0.001$ & $0.121 \pm 0.340$ & $0.066 \pm 0.164$ & 0.005 \\
\hline NLR & $2.797 \pm 1.677$ & $2.464 \pm 1.597$ & 0.002 & $2.778 \pm 1.647$ & $2.366 \pm 1.159$ & 0.013 \\
\hline PLR & $167.1 \pm 87.7$ & $160.3 \pm 85.3$ & 0.327 & $168.2 \pm 87.9$ & $152.4 \pm 66.5$ & 0.114 \\
\hline $\mathrm{PNI}$ & $46.4 \pm 5.8$ & $50.4 \pm 5.6$ & $<0.001$ & $46.5 \pm 5.8$ & $50.1 \pm 5.1$ & $<0.001$ \\
\hline
\end{tabular}

Data are presented as the mean \pm standard deviation or number (percentage) of patients

$C A R$ C-reactive protein-to-albumin ratio, CCI Charlson comorbidity index, EP elderly patient, $\mathrm{mFI}$ modified frailty index, NLR neutrophil-to-lymphocyte ratio, $P L R$ platelet-to-lymphocyte ratio, $P N /$ prognostic nutritional index, $N E P$ non-elderly patient
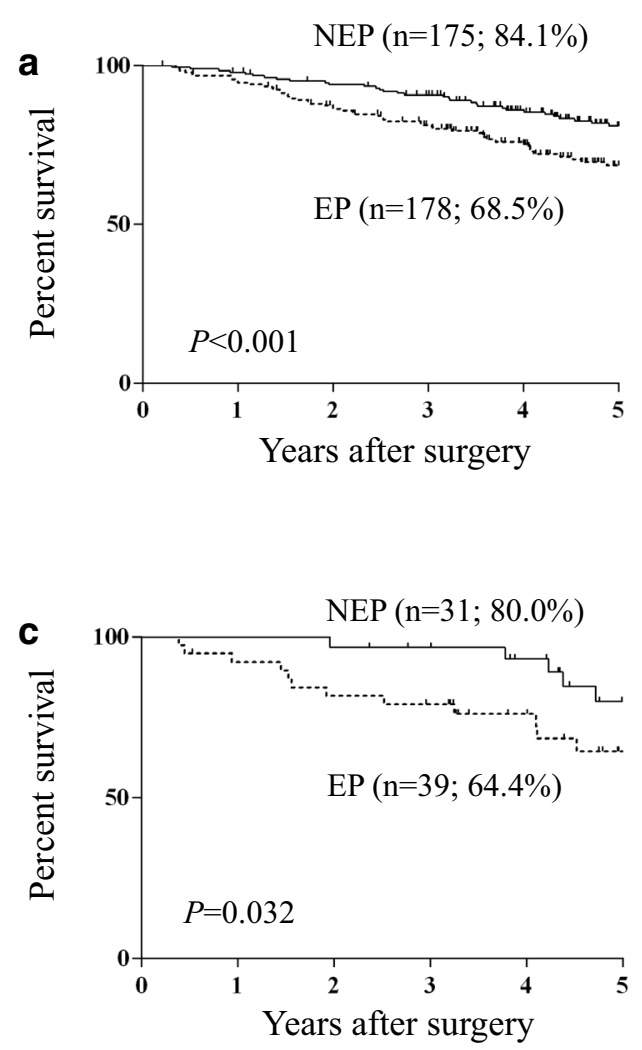
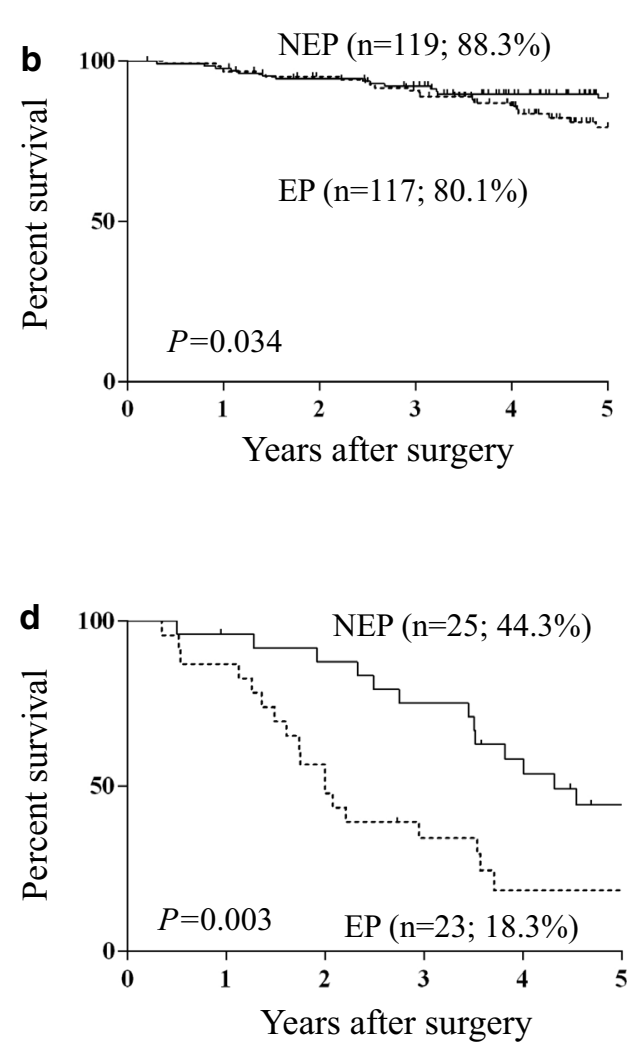

Fig. 1 Overall survival curves of all patients (a), and those classified as stage I (b), stage II (c), and stage III (d). EP elderly patient, NEP non-elderly patient

lymph node metastasis, histological type, lymphatic invasion, and venous invasion. The surgical procedure and short-term outcome in patients with stage III disease are shown in Table 3. The EP group contained significantly fewer patients who underwent
D2 lymphadectomy $(P=0.015)$ and adjuvant chemotherapy $(P<0.001)$ than the NEP group. The number of analyzed lymph nodes were significantly lower in patients in the EP group than in those in the NEP group $(P=0.005)$. Death of primary disease was 

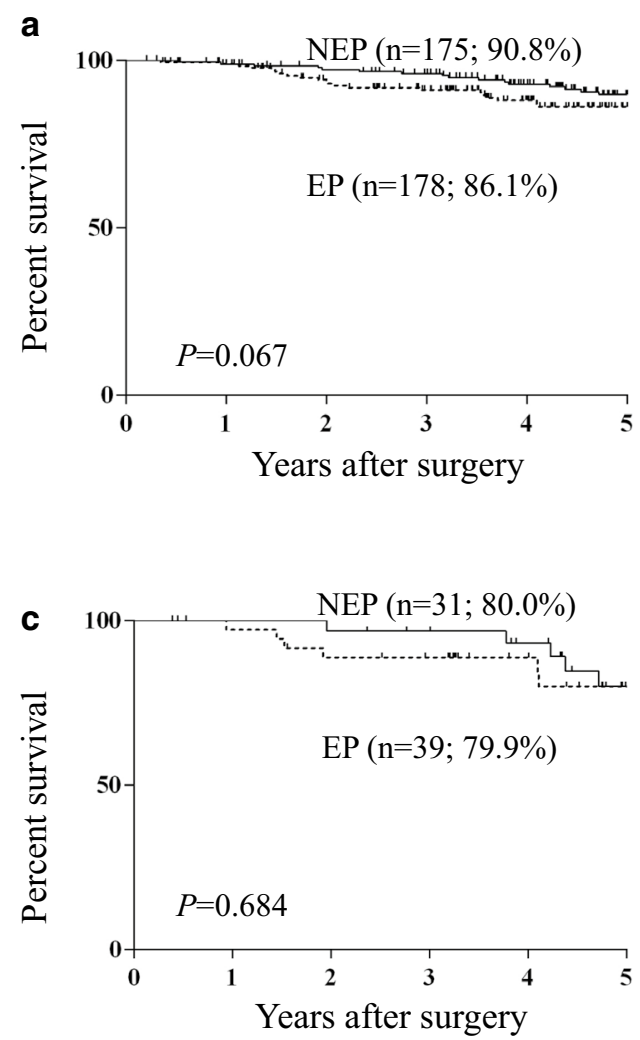
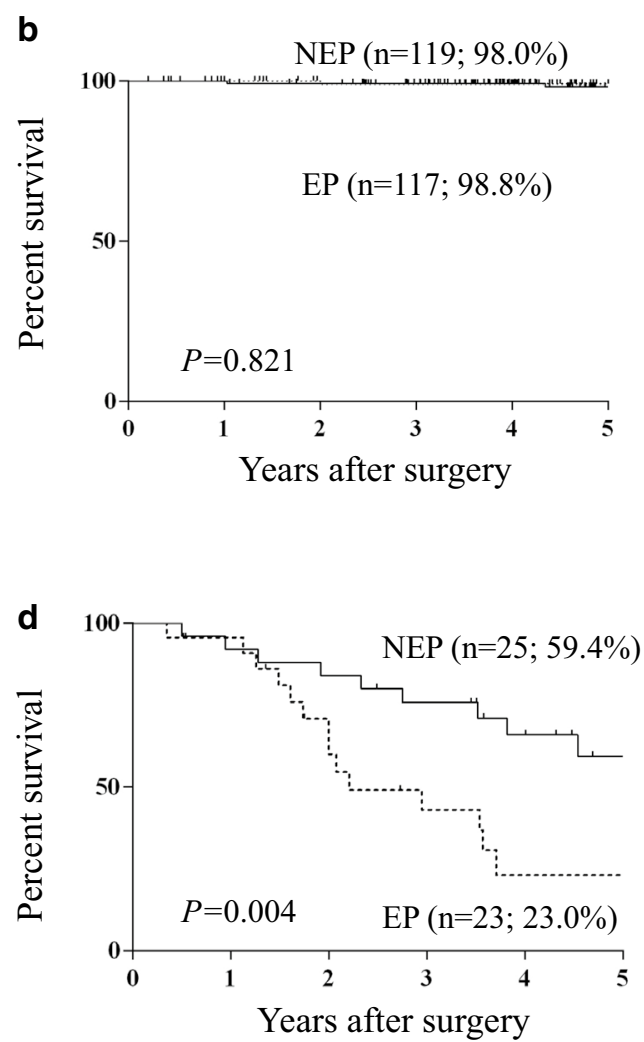

Fig. 2 Disease-specific survival curves of all patients (a), and those classified as stage I (b), stage II (c), and stage III (d). EP elderly patient, NEP non-elderly patient

significantly higher in patients in the EP group than in those in the NEP group $(P=0.043)$. No marked differences were observed in the type of gastrectomy, approach, the number of positive lymph nodes, death from another disease or in the frequency of postoperative complications. In the EP group, 5-year DSS tended to be lower in patients who did not receive adjuvant chemotherapy (38.1\%) than in those who received adjuvant therapy (11.3\%), although the difference was not significant $(\mathrm{P}=0.169)$.

\section{Systemic inflammatory response in patients with Stage III}

Clinical features including systemic inflammatory response in patients with stage III disease are shown in Table 4. CAR was significantly higher in patients in the EP group than in those in the NEP group $(P=0.046)$. Albumin and PNI were significantly lower in the EP group than in those in the NEP group $(P=0.036$ and $P=0.045$, respectively). No significant differences were observed regarding WBC, CRP, PC, NLR, and PLR.

\section{Univariate and multivariate analyses of patients with stage} III disease

We performed univariate analysis of clinicopathological factors considered prognostic for DSS in patients with stage III disease. Univariate analysis identified age, lymphatic invasion, the number of positive lymph nodes, adjuvant chemotherapy, and PNI as prognostic indicators (Table 5). Then, in the multivariate analysis, we included parameters significant at $P<0.05$ in the univariate analysis. Multivariate analysis revealed that PNI and lymphatic invasion were independent prognostic factors (Table 5).

\section{Site of recurrence in patients with stage III disease}

The site of recurrence was reviewed in patients with stage III disease, and hematogenous metastasis was significantly more frequent in the EP group than in the NEP group $(P=0.020$; Table 6). No significant differences were observed regarding peritoneal metastasis, lymph node metastasis, and local recurrence $(P=0.703, P=1.000$, and $P=0.479$, respectively; Table 6 ). Table 7 indicate the risk factor of hematogenous metastasis. Hematogenous metastasis tend to be less frequent in patients who 
Table 2 Clinicopathological characteristics of stage III patients

\begin{tabular}{|c|c|c|c|}
\hline & EP group $(n=23)$ & NEP group $(n=25)$ & $p$ value \\
\hline Age (years) & $80.5 \pm 4.9$ & $62.2 \pm 8.92$ & $<0.001$ \\
\hline Sex & & & 0.075 \\
\hline Male & $21(91.3)$ & $17(68.0)$ & \\
\hline Female & $2(8.7)$ & $8(32.0)$ & \\
\hline $\mathrm{CCl}$ & & & 0.067 \\
\hline Low & $6(26.1)$ & $13(52.0)$ & \\
\hline Moderate/severe & $17(73.9)$ & $12(48.0)$ & \\
\hline $\mathrm{mFI}$ & $0.087 \pm 0.068$ & $0.051 \pm 0.058$ & 0.068 \\
\hline Tumor size (mm) & $64.1 \pm 27.5$ & $69.9 \pm 31.2$ & 0.174 \\
\hline \multicolumn{3}{|c|}{ Depth of tumor invasion } & 0.548 \\
\hline $\mathrm{T} 1$ & 0 & 0 & \\
\hline T2 & $2(8.7)$ & $2(8.0)$ & \\
\hline T3 & $10(43.5)$ & $14(56.0)$ & \\
\hline T4 & $11(47.8)$ & $9(36.0)$ & \\
\hline \multicolumn{3}{|c|}{ Lymph node metastasis } & 0.845 \\
\hline No & 0 & 0 & \\
\hline $\mathrm{N} 1$ & $2(8.7)$ & $3(12.0)$ & \\
\hline N2 & $11(47.8)$ & $9(36.0)$ & \\
\hline N3 & $10(43.5)$ & $13(52.0)$ & \\
\hline \multicolumn{3}{|l|}{ Histologic type } & 1.000 \\
\hline Differentiated & $8(34.8)$ & $8(32.0)$ & \\
\hline Undifferenciated & $15(65.2)$ & $17(68.0)$ & \\
\hline \multicolumn{3}{|l|}{ Lymphatic invasion } & 0.214 \\
\hline ly0 & 0 & 0 & \\
\hline ly1 & $4(17.4)$ & $3(12.0)$ & \\
\hline ly2 & $8(34.8)$ & $15(60.0)$ & \\
\hline ly3 & $11(47.8)$ & $7(28.0)$ & \\
\hline \multicolumn{3}{|l|}{ Venous invasion } & 0.907 \\
\hline v0 & $2(8.7)$ & $3(12.0)$ & \\
\hline v1 & $9(39.1)$ & $10(40.0)$ & \\
\hline v2 & $9(39.1)$ & $10(40.0)$ & \\
\hline v3 & $3(13.1)$ & $2(8.0)$ & \\
\hline
\end{tabular}

Data are presented as the mean \pm standard deviation or number (percentage) of patients

$C C l$ Charlson comorbidity index, $E P$ elderly patient, $\mathrm{mFl}$ modified frailty index, NEP non-elderly patient

underwent D2 lymphadectomy, although the difference was not significant $(\mathrm{P}=0.055)$.

\section{Discussion}

In the present study, the 5-year OS rate was significantly lower in the EP group than in that in the NEP group. The 5-year DSS rates were significantly lower in stage III patients in the EP group than in those in the NEP group. CAR was significantly higher in patients in the EP group than in the NEP group, and PNI was significantly lower in patients in the EP group than in the NEP group. The
EP group contained significantly fewer patients with D2 lymphadectomy and adjuvant chemotherapy than the NEP group. Multivariate analysis revealed that PNI and lymphatic invasion were independent prognostic factors in patients with stage III disease.

In this study, the 5-year OS rate was significantly poor in the EP group. This result was similar with recent reports that elderly patients have poor physical or nutritional statuses and some degree of frailty, and are likely to die from other diseases even if gastric cancer can be cured by gastrectomy $[16,17]$. In this study, the 5-year DSS rate was significantly poor only in stage III EP group patients. However, the reason for the poor prognosis in elderly stage III gastric cancer patients has not been sufficiently elucidated, but one possible explanation is the low rate of PNI in stage III EP group patients. Sakurai et al. reviewed the prognosis of 147 elderly gastric cancer patients who underwent curative gastrectomy and showed that low preoperative PNI predicts the poor survival of patients with gastric cancer [18]. Park et al. also reviewed the prognosis of 1868 gastric cancer patients with Stage II/III who underwent gastrectomy and showed that low preoperative PNI predicts the poor survival. However, the reason for the independently significant correlation between preoperative PNI and postoperative DSS in patients with stage III is unknown. Previous studies have suggested that the inflammatory response in cancer patients is closely related to serum albumin levels and lymphocyte counts [19], and also suggest the systemic inflammatory response plays an important role in cancer development and progression [20]. Lymphocytes play an important role in immunity against tumors, and a decrease in lymphocyte count reflects a decrease in cellular immunity against cancer cells $[20,21]$. In addition, proinflammatory cytokines have been reported to decrease serum albumin production in hepatocytes and reduce serum albumin levels [22]. Therefore, PNI may be associated with prognosis because it precisely reflects systemic inflammation, and a low PNI may indicate the possibility of a high-grade malignancy. Several studies have reported that preoperative CAR and NLR elevation have been reported to be long-term poor prognostic factors for gastric cancer [14, 23, 24], but these were not found to be independent prognostic factors in stage III EP group patients in the present study.

Another possible explanation of the poor prognosis is the low rate of adjuvant chemotherapy in this population. Surgery is the mainstay in patients with gastric cancer, but the prognosis is still poor in patients with far-advanced gastric cancer such as stage III disease [6]. Therefore, adjuvant therapy may contribute to the improved survival of patients with curative gastrectomy [25]. However, side effects can result from chemotherapy 
Table 3 Surgical procedures and short-term outcomes of stage III disease

\begin{tabular}{|c|c|c|c|}
\hline & EP group $(n=23)$ & NEP group $(n=25)$ & p value \\
\hline Type of gastrectomy & & & 0.246 \\
\hline Distal & $11(47.8)$ & $12(48.0)$ & \\
\hline Total & $10(43.5)$ & $13(52.0)$ & \\
\hline Proximal & $2(8.7)$ & 0 & \\
\hline \multicolumn{4}{|l|}{ Approach } \\
\hline Laparoscopic & $5(21.7)$ & $6(24.0)$ & \\
\hline Open & $18(78.3)$ & $19(76.0)$ & \\
\hline \multicolumn{4}{|l|}{ Lymphadectomy } \\
\hline$<\mathrm{D} 2$ & $13(56.5)$ & $3(12.0)$ & \\
\hline D2 & $10(43.5)$ & $22(88.0)$ & \\
\hline The numbers of analyzed lymph nodes & $41.1 \pm 22.7$ & $55.8 \pm 22.3$ & \\
\hline The numbers of positive lymph nodes & $9.74 \pm 9.22$ & $13.0 \pm 17.6$ & \\
\hline \multicolumn{4}{|l|}{ Adjuvant chemotherapy } \\
\hline Present & $7(30.4)$ & $20(80.0)$ & \\
\hline Absent & $16(69.6)$ & $5(20.0)$ & \\
\hline \multicolumn{4}{|l|}{ Postoperative complication (CD $\geq 2)$} \\
\hline Present & $8(34.8)$ & $6(24.0)$ & \\
\hline Absent & $15(65.2)$ & $19(76.0)$ & \\
\hline \multicolumn{4}{|l|}{ Postoperative complication (CD $\geq 3$ ) } \\
\hline Present & $5(21.7)$ & $5(20.0)$ & \\
\hline Absent & $18(78.3)$ & $20(80.0)$ & \\
\hline \multicolumn{4}{|l|}{ Death from another disease } \\
\hline Present & $4(17.4)$ & $5(20.0)$ & \\
\hline Absent & $19(82.6)$ & $20(80.0)$ & \\
\hline Death from primary disease & & & 0.043 \\
\hline Present & $15(65.2)$ & $9(36.0)$ & \\
\hline Absent & $8(34.8)$ & $16(64.0)$ & \\
\hline
\end{tabular}

Data are presented as number (percentage) of patients

$C D$ Clavien-Dindo, EP elderly patient, NEP non-elderly patient

Table 4 Systemic inflammatory response in patients with stage III disease

\begin{tabular}{lccc}
\hline & EP group $(\mathbf{n = 2 3 )}$ & NEP group $(\mathbf{n = 2 5 )}$ & P-value \\
\hline WBC & $6796 \pm 2069$ & $6564 \pm 2098$ & 0.505 \\
CRP & $0.75 \pm 1.51$ & $0.43 \pm 0.65$ & 0.055 \\
Albumin & $3.73 \pm 0.49$ & $3.96 \pm 0.44$ & 0.036 \\
PC & $23.1 \pm 7.2$ & $26.3 \pm 7.8$ & 0.053 \\
CAR & $0.274 \pm 0.683$ & $0.115 \pm 0.187$ & 0.046 \\
NLR & $3.412 \pm 2.074$ & $2.902 \pm 1.440$ & 0.760 \\
PLR & $161.9 \pm 64.9$ & $181.9 \pm 90.7$ & 0.124 \\
PNI & $44.8 \pm 5.5$ & $48.0 \pm 5.4$ & 0.045 \\
\hline
\end{tabular}

Data are presented as the mean \pm standard deviation of patients

$C R P C$-reactive protein, CAR C-reactive protein-to-albumin ratio, NLR neutrophilto-lymphocyte ratio, $P C$ platelet count, $P L R$ platelet-to-lymphocyte ratio, $P N I$ prognostic nutritional index and can sometimes be severe. Furthermore, age is considered a risk factor for increased toxicity and poorer tolerance to chemotherapy. Ying et al. reported the survival benefits of adjuvant fluoropyrimidine-based chemotherapy among elderly patients with non-metastatic gastric cancer after D2 gastrectomy [26]. They reviewed the prognosis of 360 gastric cancer patients aged 65 years or older with non-metastatic gastric cancer who had undergone D2 gastrectomy, and showed that significant survival benefits were achieved with adjuvant chemotherapy in stage III patients but not in stage I or stage II patients. Mustafa et al. also reported that the addition of adjuvant chemotherapy after gastrectomy influenced survival in gastric cancer patients of $\geq 65$ years of age [27]. Based on these reports, aggressive adjuvant chemotherapy may be required even in elderly gastric cancer patients with stage III disease.

In this study, patients in the EP group underwent significantly fewer D2 lymphadenectomies than the NEP 
Table 5 Univariate and multivariate analyses of prognostic factors for disease-specific survival in patients with stage III disease

\begin{tabular}{|c|c|c|c|c|c|c|}
\hline & \multicolumn{3}{|c|}{ Univariate analysis } & \multicolumn{3}{|c|}{ Mutivariate analysis } \\
\hline & Hazard ratio & $95 \% \mathrm{Cl}$ & $P$ value & Hazard ratio & $95 \% \mathrm{Cl}$ & $P$ value \\
\hline Age $(\geqq 75 v s<75)$ & 3.200 & $1.377-7.437$ & 0.007 & 1.754 & $0.670-4.594$ & 0.252 \\
\hline Gender (Female vs Male) & 0.728 & $0.268-1.978$ & 0.534 & & & \\
\hline $\mathrm{mFI}(\geqq 0.91$ vs $<0.91)$ & 1.296 & $0.573-2.930$ & 0.534 & & & \\
\hline CCI (Moderate/severe vs Low) & 1.017 & $0.453-2.282$ & 0.967 & & & \\
\hline Lymphatic invasion (3 vs $0,1,2)$ & 3.608 & $1.584-8.214$ & 0.002 & 4.356 & $1.695-11.196$ & 0.002 \\
\hline Venous invasion $(2,3$ vs 0,1$)$ & 1.241 & $0.555-2.773$ & 0.599 & & & \\
\hline $\mathrm{pT}(4$ vs $1,2,3)$ & 2.229 & $0.992-5.010$ & 0.052 & & & \\
\hline $\mathrm{pN}(2,3$ vs 0,1$)$ & 1.683 & $0.741-3.820$ & 0.213 & & & \\
\hline The number of positive lymph node ( $\geq 5$ vs $<5$ ) & 3.517 & $1.045-11.832$ & 0.042 & 2.429 & $0.688-8.567$ & 0.168 \\
\hline Histologic type (Differenciated vs Undifferenciated & 0.448 & $0.177-1.134$ & 0.090 & & & \\
\hline Approach (Laparo vs Open) & 1.513 & $0.625-3.662$ & 0.359 & & & \\
\hline Type of gastrectomy (TG vs DG/PG) & 1.525 & $0.674-3.450$ & 0.311 & & & \\
\hline Lymphadectomy ( $\geq \mathrm{D} 2$ vs < D2) & 0.501 & $0.221-1.136$ & 0.098 & & & \\
\hline Adjuvant chemotherapy (Present vs Absent) & 0.469 & $0.211-0.963$ & 0.049 & 0.682 & $0.271-1.512$ & 0.402 \\
\hline Postoperative complication (CD3 $\geq v s<3$ ) & 1.984 & $0.589-6.689$ & 0.269 & & & \\
\hline CAR $(\geq 0.064$ vs $<0.064)$ & 0.577 & $0.229-1.458$ & 0.245 & & & \\
\hline $\operatorname{NLR}(\geq 2.273$ vs $<2.273)$ & 1.186 & $0.526-2.675$ & 0.681 & & & \\
\hline $\mathrm{PNI}(\geq 49.8$ vs $<49.8)$ & 2.760 & $1.217-8.522$ & 0.046 & 3.321 & $1.116-10.856$ & 0.047 \\
\hline
\end{tabular}

$C D$ Clavien-Dindo, $C l$ confidence interval, $D G$ distal gastrectomy, EP elderly patient, $N E P$ non-elderly patient, $P G$ proximal gastrectomy, $p T$ pathological depth of invasion, $p N$ pathological lymph node metastasis, $T G$ total gastrectomy

Table 6 Site of recurrence in patients with stage III disease

\begin{tabular}{|c|c|c|c|}
\hline & EP group $(n=23)$ & NEP group $(n=25)$ & $P$ value \\
\hline Peritoneal metastasis & & & 0.703 \\
\hline Present & $3(13.0)$ & $5(20.0)$ & \\
\hline Absent & $20(87.0)$ & $20(80.0)$ & \\
\hline Hematogenous metastasis & & & 0.020 \\
\hline Present & $7(30.4)$ & $1(4.0)$ & \\
\hline Absent & $16(69.6)$ & $24(96.0)$ & \\
\hline Lymph node metastasis & & & 1.000 \\
\hline Present & $5(21.7)$ & $5(20.0)$ & \\
\hline Absent & $18(78.3)$ & $20(80.0)$ & \\
\hline Local recurrence & & & 0.479 \\
\hline Present & $1(4.3)$ & $0(0)$ & \\
\hline Absent & $22(95.7)$ & $25(100)$ & \\
\hline
\end{tabular}

Data are presented as number (percentage) of patients

EP elderly patient, NEP non-elderly patient

group and the analyzed lymph node in patients in the EP group was significantly lower than those in the NEP group. The limited lymph node dissection in the elderly patients is another potential explanation of the poor prognosis. Complete tumor resection is essential to treat gastric cancer, and D2 gastrectomy is the standard surgical procedure for patients with advanced gastric cancer in Japan [9]. Ilfelt et al. reported that the limiting the extent of lymph node dissection affect not only lymph node recurrence but also another recurrence pattern [28]. They reviewed 711 patients who underwent curative gastrectomy, and assessed the effect of D2 compared with D1 surgery on disease recurrence and survival. They showed that regional recurrence and liver metastases 
Table 7 Risk factor of hematogenous metastasis in patients with stage III disease

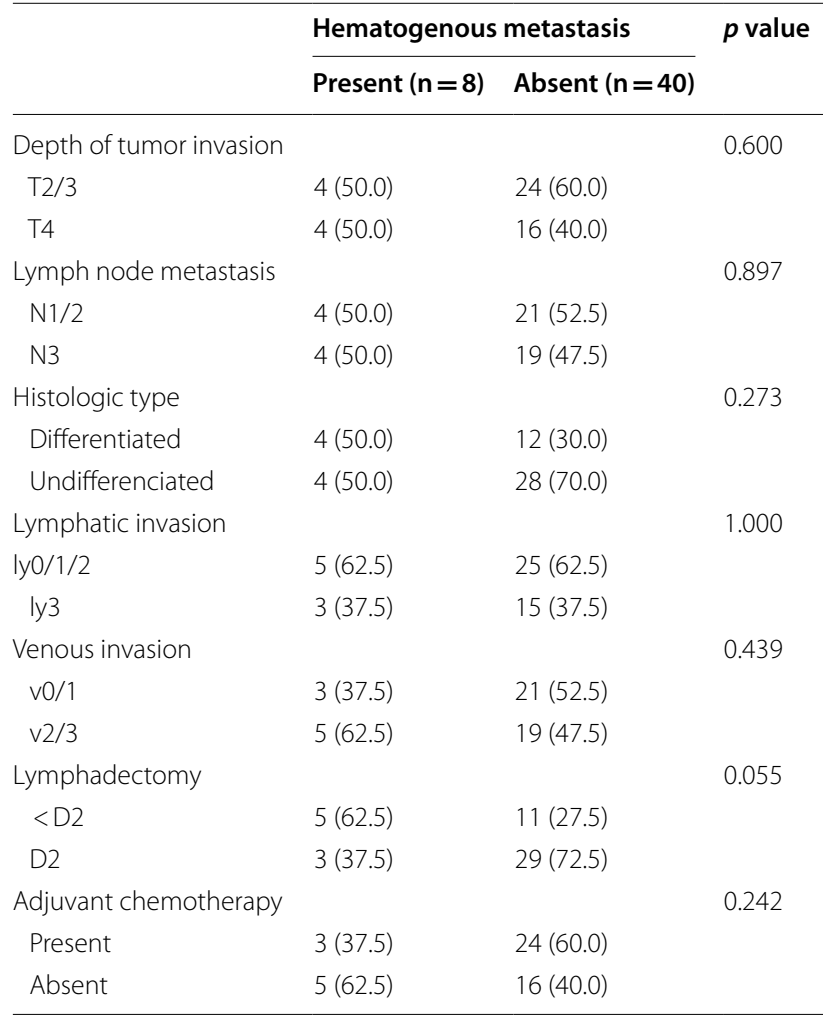

Data are presented as number (percentage) of patients

were more common in the D1 group. In this study, the hematogenous metastasis was significantly more frequent in the EP group than in the NEP group, and hematogenous metastasis tend to be less frequent in patients who underwent D2 lymphadectomy, although the difference was not significant. Therefore, aggressive D2 lymph node dissection might lead to the better prognosis.

This study had several limitations. First, this was a retrospective study that used patients' records from a single institution. Propensity score matching was used to balance the two groups, but the results must be interpreted carefully. Second, there are various definitions of the elderly patient $[16,29]$. Currently, the Japanese Geriatrics Society has proposed to redefine the elderly as 75 years of age or older, and thus we adopted a threshold of 75 years [30]. Further well-designed multicenter prospective studies with larger populations are needed to confirm these findings.

\section{Conclusion}

In conclusion, elderly gastric cancer patients with stage III disease showed poorer DSS compared with non-elderly patients, which may be due to a poorer nutritional and inflammatory background, fewer D2 lymphadenectomies, and a lack of adjuvant chemotherapy. The safe induction of standard lymphadenectomy and adjuvant chemotherapy with perioperative aggressive nutritional support may improve the prognosis of elderly gastric cancer patients.

\section{Abbreviations}

CAR: C-reactive protein-to-albumin ratio; CCl: Charlson comorbidity index; CD: Clavien-Dindo; CRP: C-reactive protein; CT: Computed tomography; DSS: Disease-specific survival; EP: Elderly patient; $\mathrm{mFI}$ : Modified frailty index; NEP: Non-elderly patient; NLR: Neutrophil-to-lymphocyte ratio; PC: Platelet count; PLR: Platelet-to-lymphocyte ratio; OS: Overall survival; PNI: Prognostic nutritional index.

\section{Acknowledgements}

We thank H. Nikki March, PhD, from Edanz Group (https://en-author-services. edanzgroup.com/) for editing a draft of this manuscript.

\section{Authors' contributions}

Study conception: TM; Study design: TM; Data acquisition: RI, WM, YS, KM, and MY; Quality control of data and algorithms: NT and SH; Data analysis and interpretation: ST and TS; Statistical analysis: TM; Manuscript preparation: TM; Manuscript editing: HS; Manuscript review: YF; Final approval of the article: all authors. All authors read and approved the final manuscript.

\section{Funding}

The authors have no financial support to declare.

\section{Availability of data and materials}

The datasets used and analyzed during the current study are available from the corresponding author on reasonable request.

Ethics approval and consent to participate

All procedures performed in this study involving human participants were in accordance with the ethical standards of the institutional review board of ethics committee and national research committee with the 1964 Helsinki declaration and its later amendments. The institutional review board of our institution approved the study (Tottori university, number 18A154). The informed consent requirement was waived.

\section{Consent to publish}

Not applicable.

\section{Competing interests}

The authors declare that they have no competing interests.

\section{Author details}

${ }^{1}$ Division of Gastrointestinal and Pediatric Surgery, Department of Surgery, School of Medicine, Tottori University Faculty of Medicine, Yonago 683-8504, Japan. ${ }^{2}$ Department of Surgery, Japanese Red Cross Tottori Hospital, Tottori 680-8517, Japan.

Received: 10 September 2020 Accepted: 1 January 2021

Published online: 09 January 2021

\section{References}

1. Bray F, Jemal A, Grey N, Ferlay J, Forman D. Global cancer transitions according to the Human Development Index (2008-2030): a populationbased study. Lancet Oncol. 2012;13(8):790-801.

2. Ferlay J, Soerjomataram I, Dikshit R, Eser S, Mathers C, Rebelo M, Parkin DM, Forman D, Bray F. Cancer incidence and mortality worldwide: sources, methods and major patterns in GLOBOCAN 2012. Int J Cancer. 2015;136(5):E359-386.

3. Orsenigo E, Tomajer V, Palo SD, Carlucci M, Vignali A, Tamburini A, Staudacher C. Impact of age on postoperative outcomes in 1118 
gastric cancer patients undergoing surgical treatment. Gastric Cancer. 2007;10(1):39-44.

4. Hayashi T, Yoshikawa T, Aoyama T, Ogata T, Cho H, Tsuburaya A. Severity of complications after gastrectomy in elderly patients with gastric cancer. World J Surg. 2012;36(9):2139-45.

5. Hamel MB, Henderson WG, Khuri SF, Daley J. Surgical outcomes for patients aged 80 and older: morbidity and mortality from major noncardiac surgery. J Am Geriatr Soc. 2005;53(3):424-9.

6. Sasako M, Sakuramoto S, Katai H, Kinoshita T, Furukawa H, Yamaguchi T, Nashimoto A, Fujii M, Nakajima T, Ohashi Y. Five-year outcomes of a randomized phase III trial comparing adjuvant chemotherapy with S-1 versus surgery alone in stage II or III gastric cancer. J Clin Oncol. 2011:29(33):4387-93.

7. Bang YJ, Kim YW, Yang HK, Chung HC, Park YK, Lee KH, Lee KW, Kim YH, Noh SI, Cho JY, et al. Adjuvant capecitabine and oxaliplatin for gastric cancer after D2 gastrectomy (CLASSIC): a phase 3 open-label, randomised controlled trial. Lancet. 2012;379(9813):315-21.

8. Yamada Y, Higuchi K, Nishikawa K, Gotoh M, Fuse N, Sugimoto N, Nishina T, Amagai K, Chin K, Niwa Y, et al. Phase III study comparing oxaliplatin plus S-1 with cisplatin plus S-1 in chemotherapy-naïve patients with advanced gastric cancer. Ann Oncol. 2015;26(1):141-8.

9. Japanese gastric cancer treatment guidelines 2014 (ver. 4). Gastric Cancer 2017, 20(1):1-19.

10. Farhat JS, Velanovich V, Falvo AJ, Horst HM, Swartz A, Patton JH Jr, Rubinfeld IS. Are the frail destined to fail? Frailty index as predictor of surgical morbidity and mortality in the elderly. J Trauma Acute Care Surg. 2012;72(6):1526-30.

11. Charlson ME, Pompei P, Ales KL, Mackenzie CR. A new method of classifying prognostic comorbidity in longitudinal studies: development and validation. J Chronic Dis. 1987;40(5):373-83.

12. Yodying H, Matsuda A, Miyashita M, Matsumoto S, Sakurazawa N, Yamada M, Uchida E. Prognostic significance of neutrophil-to-lymphocyte ratio and platelet-to-lymphocyte ratio in oncologic outcomes of esophageal cancer: a systematic review and meta-analysis. Ann Surg Oncol. 2016:23(2):646-54.

13. Onodera T, Goseki N, Kosaki G. Prognostic nutritional index in gastrointestinal surgery of malnourished cancer patients. Nihon Geka Gakkai Zasshi. 1984;85(9):1001-5.

14. Saito H, Kono Y, Murakami Y, Shishido Y, Kuroda H, Matsunaga T, Fukumoto Y, Osaki T, Ashida K, Fujiwara Y. Prognostic significance of the preoperative ratio of c-reactive protein to albumin and neutrophil-lymphocyte ratio in gastric cancer patients. World J Surg. 2018;42(6):1819-25.

15. Katayama H, Kurokawa Y, Nakamura K, Ito H, Kanemitsu Y, Masuda N, Tsubosa Y, Satoh T, Yokomizo A, Fukuda H, et al. Extended Clavien-Dindo classification of surgical complications: Japan Clinical Oncology Group postoperative complications criteria. Surg Today. 2016;46(6):668-85.

16. Hashimoto T, Kurokawa Y, Mikami J, Takahashi T, Miyazaki Y, Tanaka K, Makino T, Yamasaki M, Motoori M, Kimura Y, et al. Postoperative long-term outcomes in elderly patients with gastric cancer and risk factors for death from other diseases. World J Surg. 2019;43(11):2885-93.

17. Yang JY, Lee HJ, Kim TH, Huh YJ, Son YG, Park JH, Ahn HS, Suh YS, Kong SH, Yang HK. Short- and long-term outcomes after gastrectomy in elderly gastric cancer patients. Ann Surg Oncol. 2017;24(2):469-77.
18. Sakurai K, Tamura T, Toyokawa T, Amano R, Kubo N, Tanaka H, Muguruma K, Yashiro M, Maeda K, Ohira M, et al. Low preoperative prognostic nutritional index predicts poor survival post-gastrectomy in elderly patients with gastric cancer. Ann Surg Oncol. 2016;23(11):3669-76.

19. Crumley AB, McMillan DC, McKernan M, Going JJ, Shearer CJ, Stuart RC. An elevated $\mathrm{C}$-reactive protein concentration, prior to surgery, predicts poor cancer-specific survival in patients undergoing resection for gastrooesophageal cancer. Br J Cancer. 2006;94(11):1568-71.

20. Coussens LM, Werb Z. Inflammation and cancer. Nature. 2002;420(6917):860-7.

21. Mantovani A, Allavena P, Sica A, Balkwill F. Cancer-related inflammation. Nature. 2008;454(7203):436-44.

22. McMillan DC. Systemic inflammation, nutritional status and survival in patients with cancer. Curr Opin Clin Nutr Metab Care. 2009;12(3):223-6.

23. Allen G. Evidence appraisal of Zhang L, Liao Q, Zhang T, Dai M, Zhao Y Blood transfusion is an independent risk factor for postoperative serious infectious complications after pancreaticoduodenectomy. AORN J. 2016;104(5):465-70

24. Kinoshita A, Onoda H, Imai N, Iwaku A, Oishi M, Tanaka K, Fushiya N, Koike $\mathrm{K}$, Nishino H, Matsushima M. The C-reactive protein/albumin ratio, a novel inflammation-based prognostic score, predicts outcomes in patients with hepatocellular carcinoma. Ann Surg Oncol. 2015;22(3):803-10.

25. Yamada Y, Boku N, Mizusawa J, Iwasa S, Kadowaki S, Nakayama N, Azuma M, Sakamoto T, Shitara K, Tamura T, et al. Docetaxel plus cisplatin and S-1 versus cisplatin and S-1 in patients with advanced gastric cancer (JCOG 1013): an open-label, phase 3, randomised controlled trial. Lancet Gastroenterol Hepatol. 2019;4(7):501-10.

26. Jin Y, Qiu MZ, Wang DS, Zhang DS, Ren C, Bai L, Luo HY, Wang ZQ, Wang $\mathrm{FH}$, Li YH, et al. Adjuvant chemotherapy for elderly patients with gastric cancer after D2 gastrectomy. PLOS ONE. 2013;8(1):e53149.

27. Kucukoner M, Arpaci E, Isikdogan A, Bilici M, Uncu D, Cetin B, Dane F, Inanc M, Ekinci AS, Inal A, et al. Prognostic analysis of patients with operable gastric cancer and tolerability to adjuvant radio-chemo-therapy. Neoplasma. 2013;60(1):19-25.

28. Songun I, Putter H, Kranenbarg EM, Sasako M, van de Velde CJ. Surgical treatment of gastric cancer: 15-year follow-up results of the randomised nationwide Dutch D1D2 trial. Lancet Oncol. 2010;1 (5):439-49.

29. Ohkura Y, Haruta S, Tanaka T, Ueno M, Udagawa H. Effectiveness of postoperative elemental diet $\left(\right.$ Elenta $\left.^{\circledR}\right)$ in elderly patients after gastrectomy. World J Surg Oncol. 2016;14(1):268.

30. Ouchi Y, Rakugi H, Arai H, Akishita M, Ito H, Toba K, Kai I. Redefining the elderly as aged 75 years and older: Proposal from the Joint Committee of Japan Gerontological Society and the Japan Geriatrics Society. Geriatr Gerontol Int. 2017;17(7):1045-7.

\section{Publisher's Note}

Springer Nature remains neutral with regard to jurisdictional claims in published maps and institutional affiliations.

Ready to submit your research? Choose BMC and benefit from:

- fast, convenient online submission

- thorough peer review by experienced researchers in your field

- rapid publication on acceptance

- support for research data, including large and complex data types

- gold Open Access which fosters wider collaboration and increased citations

- maximum visibility for your research: over $100 \mathrm{M}$ website views per year

At BMC, research is always in progress.

Learn more biomedcentral.com/submissions 